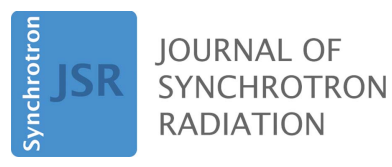

ISSN 1600-5775
Received 18 August 2021

Accepted 13 October 2021

Edited by K. Kvashnina, ESRF - The European Synchrotron, France

Keywords: extreme ultraviolet spectroscopy; X-ray absorption spectroscopy; thin films; polymers; sample preparation.

Supporting information: this article has supporting information at journals.iucr.org/s

\section{Polymer thin films as universal substrates for extreme ultraviolet absorption spectroscopy of molecular transition metal complexes}

\author{
Yusef Shari'ati and Josh Vura-Weis*
}

Department of Chemistry, University of Illinois at Urbana-Champaign, Urbana, Illinois, USA. *Correspondence e-mail: vuraweis@illinois.edu

Polystyrene and polyvinyl chloride thin films are explored as sample supports for extreme ultraviolet (XUV) spectroscopy of molecular transition metal complexes. Thin polymer films prepared by slip-coating are flat and smooth, and transmit much more XUV light than silicon nitride windows. Analytes can be directly cast onto the polymer surface or co-deposited within it. The $M$-edge XANES spectra (40-90 eV) of eight archetypal transition metal complexes $(M=$ $\mathrm{Mn}, \mathrm{Fe}, \mathrm{Co}, \mathrm{Ni}$ ) are presented to demonstrate the versatility of this method. The films are suitable for pump/probe transient absorption spectroscopy, as shown by the excited-state spectra of $\mathrm{Fe}(\mathrm{bpy})_{3}{ }^{2+}$ in two different polymer supports.

\section{Introduction}

XANES spectroscopy is a powerful tool for measuring the electronic structure of transition metal complexes. The $3 d$ metals are most commonly probed using synchrotron sources at the $K$ and $L_{2,3}$ edges, corresponding to $1 s \rightarrow$ valence and $2 p \rightarrow$ valence transitions. $M$-edge XANES, which probes $3 p \rightarrow$ valence transitions with energies between 30 and $100 \mathrm{eV}$, is much rarer due to the short penetration depth of extreme ultraviolet (XUV) photons. Over the past few years, however, the maturation of femtosecond tabletop XUV sources has renewed interest in this spectral range. The large overlap between $3 p$ and $3 d$ orbitals contributes to highly feature-rich and informative spectra, from which details on the oxidation state, spin state and ligand field of the metal-containing compound can be extracted (Groot \& Kotani, 2008; Zhang et al., 2016). M-edge XANES has been successfully used to measure excited-state dynamics in transition metal oxides (Vura-Weis et al., 2013; Jiang et al., 2014; Cirri et al., 2017; Schiffmann et al., 2020) and coordination complexes (Chatterley et al., 2016; Ryland et al., 2018, 2019; Ash et al., 2019; Zhang et al., 2019). XUV transient absorption spectroscopy has also been performed on semiconductors such as $\mathrm{Si}, \mathrm{Ge}$ and organohalide lead perovskites (Cushing et al., 2019; Lin et al., 2017; Principi et al., 2018; Cushing et al., 2020).

Further adoption of $M$-edge XANES for molecular samples is hindered by the difficulty of sample preparation. In $L$ and $K$-edge absorption spectroscopy, samples are commonly prepared as a fine powder spread by hand onto layers of Kapton (polyimide) tape, or simply pressed into $1 \mathrm{~mm}$ sample mounts with windows of the same material (Bunker, 2010). Solution-phase spectroscopy is also possible using fluid jets or flow cells (Wilson et al., 2001; Sham et al., 1989; Smith \& Saykally, 2017). Unlike soft and hard X-rays, however, the attenuation length of XUV light is of the order of only tens of 
nanometres (Henke et al., 1993); sample manipulation at this scale is challenging and the aforementioned preparation procedures do not easily apply. To date, XUV absorption spectroscopy has been limited to gas-phase molecules or those that can be deposited onto a suitable ultrathin substrate using gas-phase methods such as thermal evaporation.

Silicon nitride ('SiN', nominally $\mathrm{Si}_{3} \mathrm{~N}_{4}$ ) is one such substrate, a material traditionally used for transmission windows in X-ray absorption spectroscopy (XAS) (Borja et al., 2016; Dwyer \& Harb, 2017; Törmä et al., 2013). SiN is hard and inert, and can be fabricated with subnanometre surface roughness. $\mathrm{SiN}$ is not, however, particularly XUV transmissive - even a free-standing $100 \mathrm{~nm}$ membrane attenuates $60 \mathrm{eV}$ light by $73 \%$ [see experimental trace, Fig. $2(d)$ ]. At these thicknesses the substrates are extremely fragile and difficult to work with. Moreover, most solvents do not wet the SiN surface, which greatly hinders the casting of analyte films through techniques such as spincoating (Norrman et al., 2005). Even when spincoating does not fail, the resultant film may be deposited unevenly due to flexural standing wave patterns that spontaneously arise in the rotating SiN membrane (Advani, 1967). This film inhomogeneity interacts problematically with probebeam spatial chirp and introduces artifacts into the spectrum (Lin et al., 2016). Physical vapor deposition processes sidestep the issues with deposition from solution, but are not suitable for delicate molecules. Thermal evaporation, for example, fails with compounds that are temperature-sensitive or have counterions; these decompose before subliming. This difficulty has inspired great creativity in sample preparation, such as the deposition of cobalt oxide nanoparticles from cryogenic $\mathrm{He}$ nanodroplets (Schiffmann et al., 2020), or the use of reflec-

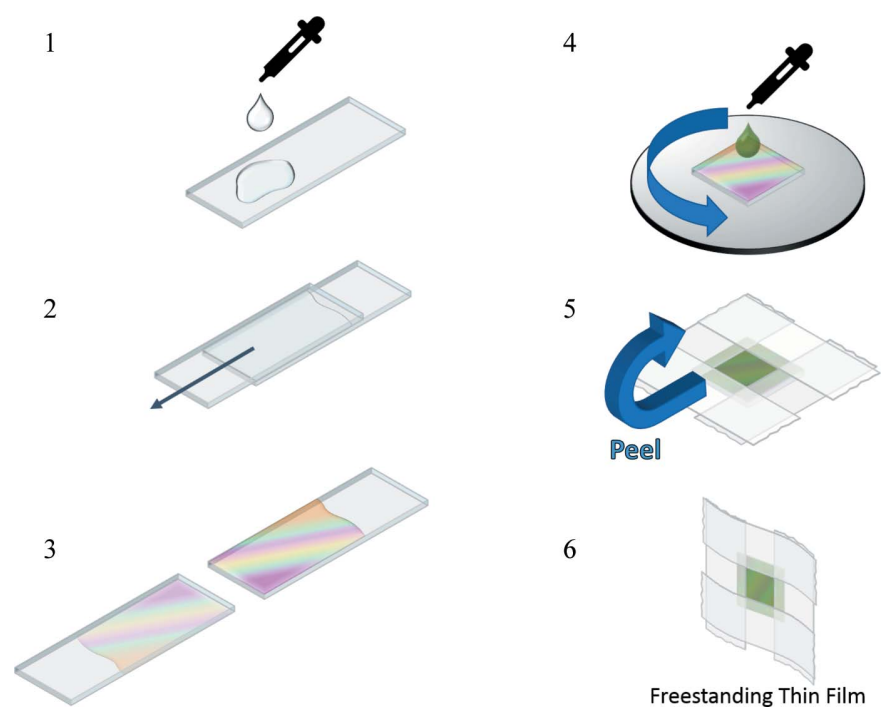

Figure 1

Schematic diagram of the slip-coating process and thin-film delamination by adhesive tape. (1) Polymer solution is applied to a glass slide substrate. (2) Polymer solution is evenly spread by slip-coating. (3) Evaporation. (4) In an optional step, analyte solution is cast upon the polymer-on-glass substrate. (5) Adhesive tape is applied to the perimeter of the polymer film; both are delaminated together from the substrate with a peeling motion. (6) This yields the freestanding thin film. tion-absorption spectroscopy from $\mathrm{Fe}^{\mathrm{III}}$ complexes dissolved in glycerol (Lin et al., 2019).

In this work we introduce new methods of sample preparation that enable XUV absorption spectroscopy to be performed on a broad range of transition metal complexes that were previously inaccessible. We show that polymer films are an attractive alternative substrate to SiN. Compared with $\mathrm{SiN}$, polymer thin films are flexible, are wetted by many solvents, and in the process described here are simple to fabricate without specialized equipment. Furthermore, the XUV transmission of the polymers explored here, polystyrene (PS) and polyvinyl chloride (PVC), are here measured to be, respectively, $\sim 60 \%$ and $\sim 100 \%$ greater than $\mathrm{SiN}$ for the same thickness.

Analytes may be cast directly onto a polymer thin-film surface or may be co-deposited from solution. The latter dispersal method embodies a 'solid solution' in which analyte molecules are well separated from one another and is especially useful for compounds that show large electronic changes or fluorescence quenching upon aggregation in the solid state (Ito et al., 2018). Such solid-state solvation in polymer films has been shown to be important for the energetics and dynamics of optoelectronic materials (Delor et al., 2017).

\section{Experimental details}

\subsection{M-edge XANES}

The XUV probe is generated via high-harmonic generation (HHG) in an instrument described previously (Zhang et al., 2016). Briefly, a Ti:sapphire laser produces $4 \mathrm{~mJ}$ pulses of $800 \mathrm{~nm}$ light at a $1 \mathrm{kHz}$ repetition rate with a pulse width of 35 fs FWHM. The IR laser pulses are focused into a semiinfinite gas cell filled with either neon or argon. Fig. S3(A) in the supporting information shows the XUV continuum created in the HHG process. The continuum has intensity in the range $40-90 \mathrm{eV}$, with the flux maximum at an energy that depends on the gas used. The $525 \mathrm{~nm}$ pump for transient experiments is produced by diverting a $0.7 \mathrm{~mJ}$ portion of the Ti:sapphire beam to a noncollinear optical parametric amplifier (TOPAS White). A stream of low-pressure nitrogen gas was passed across the samples to avoid pump-induced heating.

\subsection{Polymer thin-film fabrication}

While polymer films may be prepared in many ways, this study focuses on film fabrication by 'slip-coating' (Fig. 1, steps $1-3)$, a procedure in which liquid solution is drawn out from between sliding glass plates. Slip-coating - like dip-coating, doctor-blading or flow-coating (Stafford et al., 2006) - is a meniscus-guided deposition technique (Gu et al., 2018). The solution to be cast is loaded between two horizontal parallel plates, with the top plate freely supported by the liquid beneath (Fig. 1, step 1). Capillary forces constrain the liquid and cause it to coat the plates evenly, while the gap height is maintained approximately constant by the incompressible volume of liquid. The top plate is slipped off manually and 
frictional drag forces draw out the solution, leaving a wet film on the surface (Fig. 1, step 2). Evaporation yields the dry thin film. An iridescent coloration often develops at this stage due to thin-film interference (Fig. 1, step 3). The coated substrate is framed with adhesive tape which is then carefully peeled off the glass, taking the polymer with it and yielding the freestanding film (Fig. 1, steps 5-6). Alternatively, slow immersion of the plate into water at an angle of $45^{\circ}$ releases the film from its glass substrate to float on the surface, from where it is easily retrieved. Photographs of these operations and the resultant films are shown in Fig. S1.

Slip-coating is simple, fast and inexpensive, and yields films of good quality for XUV transmission absorbance spectroscopy. Film thickness is controlled by adjusting the polymer solution concentration and the plate velocity during deposition (Landau \& Levich, 1942; Davis et al., 2014), with accessible thicknesses ranging from a few tens of nanometres to several micrometres. The thickness of the prepared films is readily determined by fitting the visible-light interference pattern (Huibers \& Shah, 1997), as detailed in the supporting information.

\subsection{Suitability of polymer films}

The ideal sample substrate has a large XUV transmissivity, is smooth and homogeneous over the length scales of both the XUV probe and the overall sample, and accommodates a wide variety of analytes either within its matrix or upon its surface. This section evaluates the degree to which polymer films fulfill these criteria.

2.3.1. XUV characterization. Due to the velocity gradient during manual plate separation, slip-coated polymer films show a thickness gradient over the scale of the substrate ( $75 \mathrm{~mm} \times 25 \mathrm{~mm}$ glass slide), from which a region of the desired thickness may be selected (see Fig. S1). Fig. 2(a) shows the XUV absorbance profile of a typical PS film sample. The thickness varies only slightly over the $9 \mathrm{~mm}^{2}$ sample area, with a standard deviation of $2.2 \%$. On the even smaller scale of the $\sim 75 \mu \mathrm{m}$ FWHM XUV beam, the film thickness is essentially constant - an important criterion for mitigating spectral artifacts which arise from sample and probe-beam spatial inhomogeneities (Lin et al., 2016). Unlike films prepared from spincoating on flexible substrates, there is no evidence of standing wave patterns in the thickness profile. While films produced in this way are homogeneous on the scales necessary for XUV spectroscopy, greater homogeneity and reproducibility could be achieved, at the cost of greater complexity, by using a computer-controlled actuator to move the plates at a precise velocity (Stafford et al., 2006).

The XUV absorbance spectrum was acquired and compared with that of $100 \mathrm{~nm} \mathrm{SiN} \mathrm{membranes.} \mathrm{Fig.} \mathrm{2(b)} \mathrm{shows} \mathrm{the}$ XUV spectrum of these materials, which in the energy range observed comprises only non-resonant absorption due to photoionization of valence electrons. This photoionization is well approximated by a power law and the absorbance is found to be directly proportional to thickness, as shown in Fig. 2(c). While the polymers absorb significantly less XUV radiation than does $\mathrm{SiN}$ per unit thickness ( $\sim 40 \%$ less for PS and $\sim 50 \%$ less for PVC at $60 \mathrm{eV}$ ), calculations based on atomic scattering values [shown in Fig. 2(d)] underestimate polymer absorbance and overestimate SiN absorbance (CXRO Database; Henke et al., 1993). In the case of the polymers, this discrepancy might be accounted for by a different thin-film density from that of the bulk polymer, or by an increased photoionization cross section of the polymer molecular orbitals compared with isolated atoms (Vignaud et al., 2014). In contrast to the simulation of $\mathrm{Si}_{3} \mathrm{~N}_{4}$, the material used, 'SiN,' is actually substoichiometric in nitrogen. Indeed, a formulation of $\mathrm{Si}_{3} \mathrm{~N}_{3.4}$ better fits the data.

2.3.2. Polymer films as substrate. PS and PVC films present a surface more easily wetted by organic solvents than SiN. Before the film is delaminated, various analyte compounds may be cast upon it by e.g. spin-, slip- or drop-casting. However, exposure to solvents that dissolve or swell the polymer (such as dichloromethane or tetrahydrofuran) mars the surface and/or prevents the film from delaminating. This can be avoided by appropriate solvent choice and by reducing the time the solvent is in contact with the polymer. Typically, we accomplish this by spin-coating (Fig. 1, step 4) with immediate application of a heat gun to remove solvent quickly, which also limits the crystallite size and results in a smoother film. We found that a 4:2:1 mixture of methanol:propan-2ol:butanol is an effective solvent system for many analytes; it also evaporates quickly and efficiently wets the polymer surfaces, yet is slow to mar them.

After a second layer is cast upon the polymer base layer, the resulting bilayered film can be delaminated in one piece. PVC
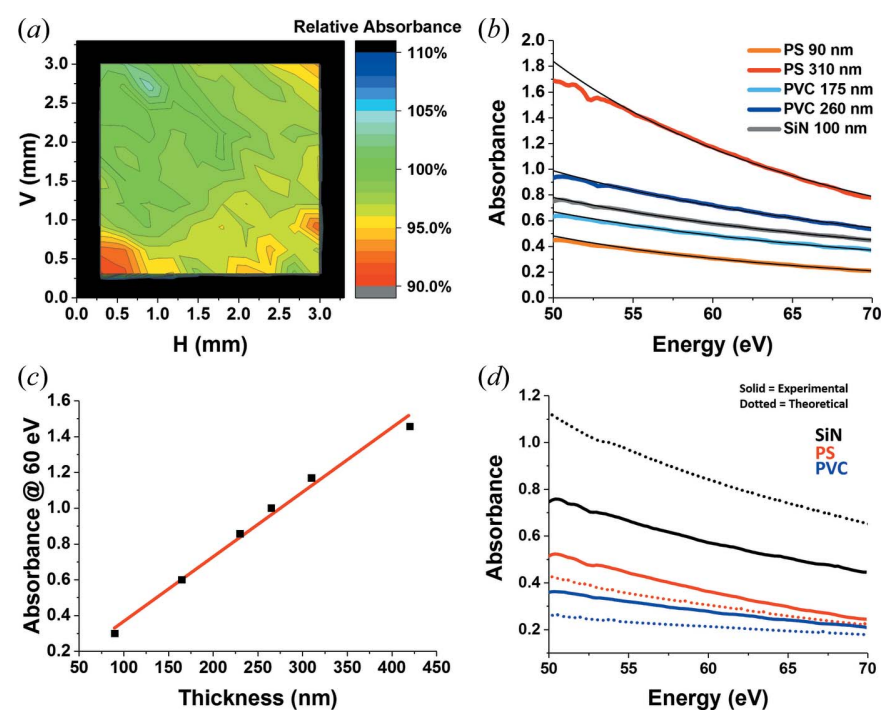

Figure 2

(a) A $225 \mathrm{~nm}$ polystyrene thin film mounted on an empty Si frame. The XUV absorbance was sampled on a $200 \mu \mathrm{m}$ interval grid to build up an image. Contour lines indicate $1 \%$ changes in relative absorbance. (b) Polymer and SiN film XUV spectra. Black lines are power law fits to the data. (c) The XUV absorbance of PS as a function of thickness. The solid line is a linear fit to the data with a $y$ intercept of 0 and a slope of $(3.61 \pm 0.08) \times 10^{-3} \mathrm{~nm}^{-1}$. (d) XUV spectra of $100 \mathrm{~nm}$ thick samples, as predicted from CXRO data (dotted lines), versus spectra constructed from the experimentally determined absorption coefficients (solid lines). 
films readily delaminate from glass with adhesive tape (Fig. 1, step 5). Alternatively, water flotation delaminates both PVC and PS. In some cases, PS films may also be removed with adhesive tape, though they generally adhere to the glass more strongly. All PVC bilayer films prepared in this study were removed with adhesive tape.

2.3.3. Polymer films as matrix. Samples may be prepared by co-deposition into a single-layer film, in which the polymer acts as a bulk matrix supporting the analyte. With high analyte loading, the resultant films are no longer removable with adhesive tape and are prone to tearing. Such films must be delaminated by water flotation. If water-soluble, some analyte inevitably leaches out of films when prepared in this way. Very water-sensitive analytes are better prepared on PVC films, which can be delaminated mechanically.

\section{Results and discussion}

The versatility of this sample preparation method is demonstrated using the eight representative coordination complexes shown in Fig. 3, representing several archetypes of molecules that can now be studied easily using $M$-edge XANES.

\subsection{Ground-state XUV spectroscopy}

The $M$-edge XANES spectrum of each sample was collected and all are shown in Fig. 4. Each spectrum shows a resonant absorption edge whose position is primarily determined by element identity and oxidation state. Multiplet features on top of the edge are shaped by analyte oxidation state, spin state and coordination geometry (Zhang et al., 2016). Spectra have been baselined by subtraction of a powerlaw fit to the pre-edge region, corresponding to the nonresonant photoionization of substrate and ligand atoms. Following the main feature, metal $3 p$ photoionization to the continuum contributes to the non-zero cross section and diminishes approximately as a power law thereafter.

Figs. 4(a1) and 4(a2). The molecular cobalt oxide cluster $\left[\mathrm{Co}_{4}{ }_{4} \mathrm{O}_{4}\right](\mathrm{OAc})_{4}(\mathrm{py})_{4}(\mathrm{OAc}=$ acetate, $\mathrm{py}=$ pyridine $)$, or 'cubane' [Fig. 3(a)], has garnered much interest since its isolation (Beattie et al., 1998) as a model for the cobaltphosphate (CoPi) system of Nocera (Kanan \& Nocera, 2008), as well as as a potential water oxidation catalyst in its own right (Smith et al., 2015; Nguyen et al., 2015; Ullman et al., 2014; Nguyen et al., 2017). As one of the few complexes capable of supporting a stable $\mathrm{Co}^{\mathrm{IV}}$ center (McAlpin et al., 2011), cubane and its oxidized analogs have been the subject of prior X-ray absorption studies, including Co $1 s 3 p(K \beta)$ resonant inelastic X-ray scattering (RIXS), which probes the same final state as $M$-edge XANES (Brodsky et al., 2017; Hadt et al., 2016). In those studies, samples were prepared as either a solid powder in a $1 \mathrm{~mm}$ cell with Kapton windows, or as $2 \mathrm{~m} M$ solutions in acetonitrile contained within a 3D-printed spectroelectrochemical cell.

Cubane decomposes at temperatures too low $\left(\mathrm{ca} 120^{\circ} \mathrm{C}\right)$ for sample preparation by thermal evaporation but is easily prepared with polymer films. We report in Figs. 4(a1) and
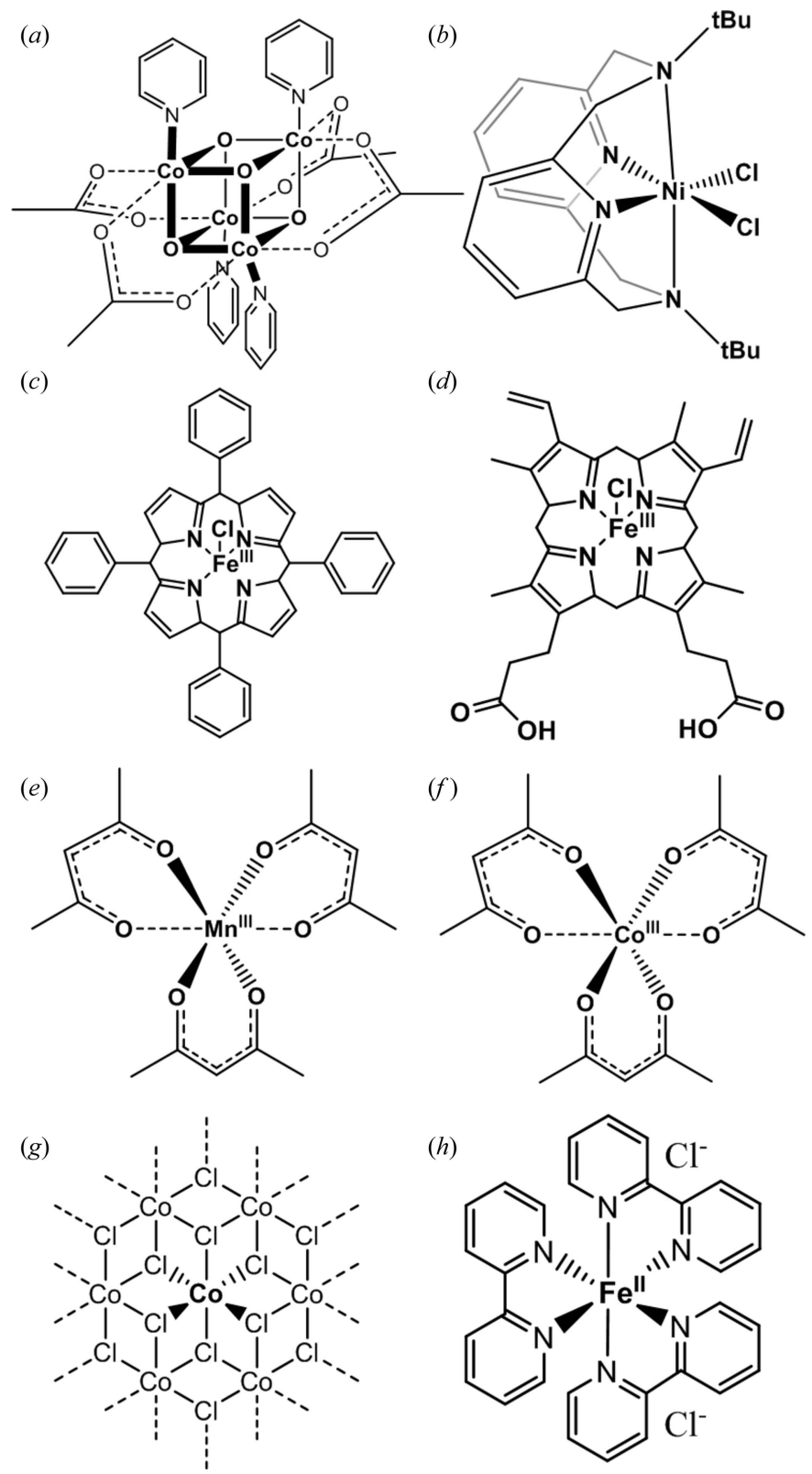

Figure 3

The chemical structures of $(a)$ cobalt cubane $\left[\mathrm{Co}^{\mathrm{III}}{ }_{4} \mathrm{O}_{4}\right],(b)\left({ }^{t} \mathrm{BuN}_{4}\right)$ $\mathrm{Ni}^{\mathrm{II}} \mathrm{Cl}_{2}$, (c) $\mathrm{Fe}^{\mathrm{III}} \mathrm{TPPCl},(d)$ hemin, (e) $\mathrm{Mn}^{\mathrm{III}}(\mathrm{acac})_{3},(f) \mathrm{Co}^{\mathrm{III}}(\mathrm{acac})_{3}$, (g) $\mathrm{Co}^{\mathrm{II}} \mathrm{Cl}_{2}$ and $(h) \mathrm{Fe}^{\mathrm{II}}(\mathrm{bpy})_{3} \mathrm{Cl}_{2}$.

4(a2) the ground-state $M$-edge XANES spectra of cubane samples, both incorporated into PS films and deposited upon PVC. In either case, the low-spin cobalt atoms of cubane exhibit a main peak at $64.3 \mathrm{eV}$ and a second at $73 \mathrm{eV}$. Except for a slight spectral broadening in the cubane/PS co-deposited sample, the position and intensity of the features are very similar between these sample preparation methods, indicating a relative insensitivity to the sample environment.

Fig. 4(b). The complex $\left({ }^{t} \mathrm{BuN}_{4}\right) \mathrm{Ni}^{\mathrm{II}} \mathrm{Cl}_{2}\left[{ }^{t} \mathrm{BuN}_{4}=N, N^{\prime}\right.$-di-tertbutyl-2,11-diaza[3.3](2,6)pyridinophane] in Fig. 3(b) serves as an example of a soluble organic nickel-containing compound, and is a convenient starting point for the formation of $\mathrm{Ni}^{\mathrm{I}}$ and $\mathrm{Ni}^{\mathrm{III}}$ catalysts relevant to Kumada and Negishi cross-coupling 

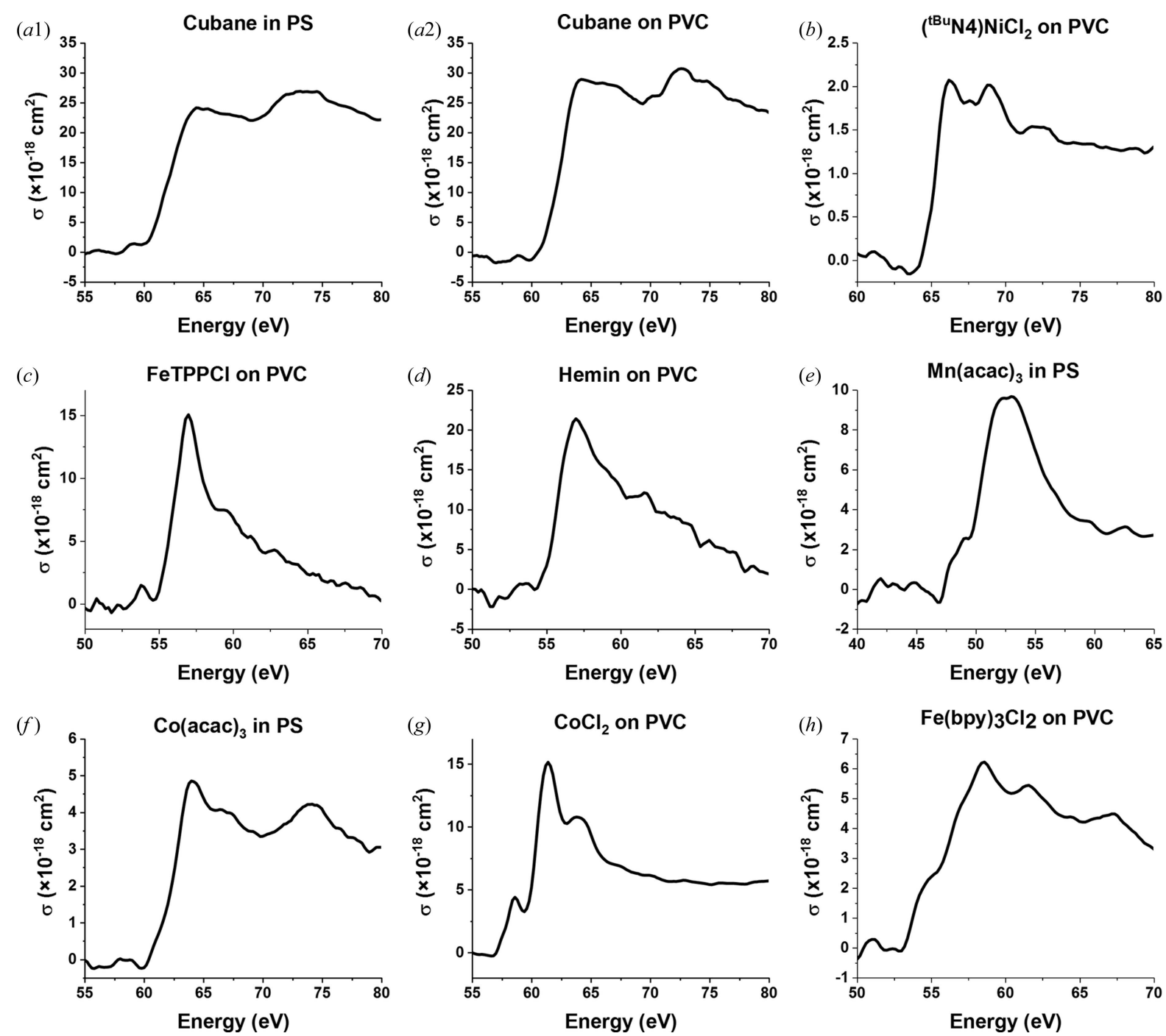

Figure 4

XUV spectra obtained from analytes deposited on the surface of PVC, or co-deposited in PS.

reactions (Khusnutdinova et al., 2013; Zheng et al., 2014). As shown in Fig. 4(b), the $M$-edge XANES spectrum of $\left({ }^{t} \mathrm{BuN}_{4}\right) \mathrm{Ni}^{\mathrm{II}} \mathrm{Cl}_{2}$ has two prominent peaks at 66.2 and $68.9 \mathrm{eV}$, consistent with prior reports of $\mathrm{Ni}^{\mathrm{II}}$ compounds with triplet ground states (Wang et al., 2013; Cirri et al., 2017).

Figs. 4(c) and 4(d). Porphyrins have been studied for light harvesting (Imahori, 2004) and phototherapy (Josefsen \& Boyle, 2008), and as catalysts for diverse reactions such as oxygen or hydrogen evolution (Zhang et al., 2017). The two porphyrin compounds examined here, iron(III) tetraphenyl porphyrin chloride $\left(\mathrm{Fe}^{\mathrm{III}} \mathrm{TPPCl}\right)$ and iron(III) protoporphyrin IX chloride (hemin), are shown in Figs. 3(c) and 3(d), respectively. In a previous study from our laboratory, $\mathrm{Fe}^{\mathrm{III}} \mathrm{TPPCl}$ samples were prepared by thermal evaporation and the ultrafast relaxation dynamics were investigated by transient $M$-edge XANES (Ryland et al., 2018), but the carboxylic acid groups on hemin preclude its sublimation at reasonable temperatures.

The low solubility of $\mathrm{Fe}^{\mathrm{III}} \mathrm{TPPCl}$ limits the concentration of material, and hence the signal strength, that can be achieved in a PS matrix. Deposition upon PVC was also problematic, as dichloromethane (DCM) - one of the best solvents for porphyrins - is not suitable for constructing bilayers in this way. Even very short exposure to DCM mars the smooth polymer surface and prevents delamination from glass. However, it was found that a thin $\mathrm{Fe}^{\mathrm{III}} \mathrm{TPPCl}$ film could be spin-coated onto glass from DCM and this neat $\mathrm{Fe}^{\mathrm{III}} \mathrm{TPPCl}$ film easily delaminates and floats when slowly immersed into water. This process is like that of polymer delamination and may be generally applicable to hydrophobic glass coatings (Khodaparast et al., 2017). The neat Fe ${ }^{\mathrm{III}} \mathrm{TPPCl}$ film, which is estimated to be $<100 \mathrm{~nm}$ by its gray-to-golden reflection, is exceedingly brittle and cannot be lifted from the water's surface without destruction. However, it can be successfully picked up upon a thin film support brought up from below. Multiple layers of sample can be built up by repeating the process as desired. This method was employed to produce the PVC-supported sample of Fig. 4(c).

Hemin, in contrast, did not require this layer-by-layer process: its carboxylic acid side groups enable its facile 
dissolution in alkaline solutions. Samples were prepared by spin-coating upon PVC from a mixed-alcohol solution containing a small amount of triethylamine.

As shown in Fig. 4(c), the main peak of $\mathrm{Fe}^{\mathrm{III}} \mathrm{TPPCl}$ appears at $57 \mathrm{eV}$, with a smaller pre-edge feature at $53.8 \mathrm{eV}$. The position of the main peak in hemin is identical to that in $\mathrm{Fe}^{\mathrm{III}} \mathrm{TPPCl}$, but its trailing edge diminishes more slowly and widens the feature. The hemin pre-peak [Fig. $4(d)$ ], if it exists, is not resolved.

Figs. $4(e)$ and $4(f) . M(\text { acetylacetonate })_{3}$ complexes are classic coordination compounds, and lend themselves well to fundamental investigations into electronic structure (DiazAcosta et al., 2001, 2003; Carlotto et al., 2017) and validation of spectroscopic techniques (Kubin, Kern et al., 2018; Kubin, Guo et al., 2018; Zhang et al., 2016). The low-spin $\mathrm{Co}^{\mathrm{III}}(\mathrm{acac})_{3}$ served as a useful reference in a study showcasing the $M$-edge XANES spectrum of several cobalt compounds. Samples were prepared by thermal evaporation onto SiN membranes (Zhang et al., 2016). This and the high-spin $\mathrm{Mn}^{\mathrm{III}}(\mathrm{acac})_{3}$ are similarly used here, with samples prepared by co-deposition from PS solution. Fig. 4(e) shows the $M$-edge XANES spectrum of $\mathrm{Mn}^{\mathrm{III}}(\mathrm{acac})_{3}$, whose main feature centers at $52.6 \mathrm{eV}$. A slight shoulder cleaves from this main peak at $49.0 \mathrm{eV}$. The spectrum of the cobalt analog is shown in Fig. $4(f)$ and displays a three-peaked structure, with peaks at $64.0,67$ and $74 \mathrm{eV}$. In comparison with the similarly low-spin $d^{6}$ cobalt cubane spectra of Figs. 4(a1) and 4(a2), the peaks of $\mathrm{Co}^{\mathrm{III}}(\mathrm{acac})_{3}$ are at similar positions, though are slightly sharper and differ in relative intensity, probably due to the more rigidly octahedral symmetry of the acetylacetonate complex.

Fig. $4(g) . \mathrm{Co}^{\mathrm{II}} \mathrm{Cl}_{2}$ is a high-spin polymeric ionic compound with the $\mathrm{Co}^{2+}$ ions assuming octahedral geometry [Fig. 3(g)]. Aside from X-ray studies motivated by fundamental interest in its ground-state electronic configuration (Kikas et al., 1999; Wang et al., 2017), $\mathrm{Co}^{\mathrm{II}} \mathrm{Cl}_{2}$ is useful as a precursor in the production of cobalt oxide and cobalt metal thin films (Väyrynen et al., 2018). The $M$-edge XANES spectrum of $\mathrm{Co}^{\mathrm{II}} \mathrm{Cl}_{2}$ is shown in Fig. 4(g), displaying two large features at 61.4 and $63.8 \mathrm{eV}$, and a smaller one at $58.6 \mathrm{eV}$.

Fig. $\mathbf{4}(\boldsymbol{h})$. $\mathrm{Fe}^{\mathrm{II}}(\mathrm{bpy}){ }_{3} \mathrm{Cl}_{2}\left[\mathrm{bpy}=2,2^{\prime}\right.$-bipyridine; Fig. $\left.3(h)\right]$ and similar $\mathrm{Fe}$ polypyridyl complexes are the subject of intense scrutiny due to their ultrafast intersystem crossing rates. Although ruthenium polypyridyl complexes have metal-toligand charge-transfer (MLCT) states with lifetimes of the order of hundreds of nanoseconds to a microsecond (Juris $e t$ al., 1988), their iron congeners relax in less than 200 fs to lowenergy triplet and quintet metal-centered states (Auböck \& Chergui, 2015). The former are excellent chromophores in dye-sensitized solar cells and in photoredox chemistries but the latter compounds, attractively earth-abundant and inexpensive, are inefficient due to these short lifetimes (Ardo \& Meyer, 2009; Wenger, 2019; McCusker, 2019). This discrepancy has driven research into better understanding the excited-state surfaces that drive these dynamics (Miaja-Avila et al., 2016; Zhang et al., 2019; Auböck \& Chergui, 2015). The $\mathrm{Fe}^{\mathrm{II}}(\mathrm{bpy})_{3} \mathrm{Cl}_{2}$ samples were here prepared by spin-coating from solution onto PVC. The ground-state $M$-edge XANES spectrum [Fig. 4(h)] displays three main peaks and a shoulder at $58.4,61.6,67.4$ and $55.0 \mathrm{eV}$, respectively.

\subsection{Transient XUV spectroscopy}

Efforts to improve iron(II) polypyridyl complexes have focused on altering the problematic intermediate states on the relaxation pathway through rational ligand design (Chábera et al., 2018; Wenger, 2019; McCusker, 2019). However, directly observing and characterizing these states requires a technique with ultrafast time resolution and spin sensitivity. We recently used $M$-edge XANES to identify an intermediate ${ }^{3} T$ state and coherent oscillations on the ${ }^{5} T_{2 g}$ surface in $\mathrm{Fe}^{\mathrm{II}}(\text { phen })_{3}(\mathrm{SCN})_{2}$ (phen $=o$-phenanthroline) (Zhang et al., 2019). Unlike the fortuitously sublimable phenanthroline compound, thin films of other iron(II) polypyridyl compounds, including the oftstudied prototypical spin-crossover compound $\mathrm{Fe}^{\mathrm{II}}(\mathrm{bpy})_{3} \mathrm{Cl}_{2}$, are not so easily prepared.

The sample preparation methods developed here enabled collection of the transient $M$-edge XANES spectra of two $\mathrm{Fe}^{\mathrm{II}}(\text { bpy })_{3}{ }^{2+}$ compounds: $\mathrm{Fe}^{\mathrm{II}}(\text { bpy })_{3} \mathrm{Cl}_{2}$ cast on $\mathrm{PVC}$ and $\mathrm{Fe}^{\mathrm{II}}(\mathrm{bpy})_{3}\left(\mathrm{PF}_{6}\right)_{2}$ co-deposited in PS. Samples were pumped into the MLCT band at $525 \mathrm{~nm}$ and the difference spectra collected at delay times when the ${ }^{5} T_{2 g}$ state is fully populated, between 1.0 and 2.0 ps (Auböck \& Chergui, 2015). Fig. 5 shows the difference spectra for these two $\mathrm{Fe}^{\mathrm{II}}(\mathrm{bpy})_{3}{ }^{2+}$ samples compared with the previously published ${ }^{5} T_{2 g}$ difference spectrum for $\mathrm{Fe}^{\mathrm{II}}(\mathrm{phen})_{3}(\mathrm{SCN})_{2}$. The spectra exhibit a positive excited-state absorption signal near $57.1 \mathrm{eV}$, with a shoulder at $55.3 \mathrm{eV}$ that is more sharply defined in the bipyridine complexes. Each spectrum also displays a groundstate bleach near $67.5 \mathrm{eV}$. The successful acquisition of these spectra underscores the versatility of polymer films, as well as the aptitude of $M$-edge XANES spectroscopy towards the determination of excited-state electronic structure in metal complexes. The way is now made clear towards the future measurement of further spin-crossover compounds.

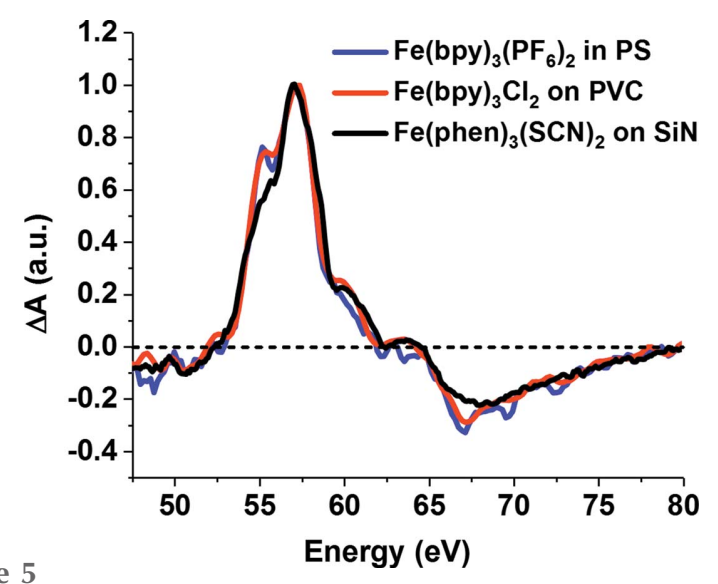

Figure 5

The normalized excited-state difference spectra of iron polypyridyl compounds. The red line shows $\mathrm{Fe}(\mathrm{bpy})_{3} \mathrm{Cl}_{2}$ on $\mathrm{PVC}$, time-averaged between 1.0 and $2.0 \mathrm{ps}$. The blue line shows $\mathrm{Fe}^{\mathrm{II}}(\mathrm{bpy})_{3}\left(\mathrm{PF}_{6}\right)_{2}$ in PS, timeaveraged between 1.0 and $2.0 \mathrm{ps}$. The black line gives the spectral component of the global fit to $\mathrm{Fe}^{\mathrm{II}}(\text { phen })_{3}(\mathrm{SCN})_{2}$ data corresponding to the ${ }^{5} T_{2 g}$ state. 


\section{Conclusions}

The growing development of HHG sources of XUV radiation permits core-level spectroscopy to be performed using convenient in-laboratory instruments on femtosecond to attosecond timescales (Geneaux et al., 2019; Zhang et al., 2016). These advantages are balanced by the requirements that the samples be ultrathin and smooth. Limited sample preparation protocols have held back development in this area and $M$-edge XANES spectroscopy has so far been restricted to those materials that can be evaporated onto hard substrates such as $\mathrm{Si}_{3} \mathrm{~N}_{4}$ or otherwise amenable to gas-phase experiments. We have now demonstrated a new technique for solution-processable sample deposition, enabling acquisition of $M$-edge spectra of many previously inaccessible compounds, shown here with the example of eight model compounds.

The polystyrene and polyvinyl chloride polymer substrates used here are easily fabricated in a simple slip-coating technique. They are flexible and highly XUV transmissive, and have more favorable wetting properties than silicon nitride. The polymers accommodate a wide variety of analytes, either directly cast upon the surface or dissolved within the bulk of the polymer thin film. Such samples are homogeneous, ultrathin and smooth, mitigating harmonic spectral artifacts and enabling the acquisition of high-quality ground- and excitedstate XUV spectra.

This technique significantly broadens the types of molecular complexes that can be studied with $M$-edge XANES.

\section{Related literature}

For further literature related to the supporting information, see Andersen et al. (2001), Chakrabarty et al. (2007), Chiuzăian et al. (2005), Jaeger \& van Dijk (1936) and Jones et al. (2013).

\section{Funding information}

This material is based upon work supported by the US Department of Energy, Office of Science, Office of Basic Energy Sciences under award No. DE-SC0018904, and upon work supported by the National Science Foundation Graduate Research Fellowship under grant No. DGE-1746047. The XUV instrument was built with partial funding from the Air Force Office of Scientific Research under AFOSR award Nos. FA9550-14-1-0314 and FA9550-18-1-0293.

\section{References}

Advani, S. H. (1967). Int. J. Mech. Sci. 9, 307-313.

Andersen, P., Andersen, T., Folkmann, F., Ivanov V, K., Kjeldsen, H. \& West, J. B. (2001). J. Phys. B, 34, 2009-2019.

Ardo, S. \& Meyer, G. J. (2009). Chem. Soc. Rev. 38, 115-164.

Ash, R., Zhang, K. \& Vura-Weis, J. (2019). J. Chem. Phys. 151, 104201.

Auböck, G. \& Chergui, M. (2015). Nat. Chem. 7, 629-633.

Beattie, J. K., Hambley, T. W., Klepetko, J. A., Masters, A. F. \& Turner, P. (1998). Polyhedron, 17, 1343-1354.
Borja, L. J., Zürch, M., Pemmaraju, C. D., Schultze, M., Ramasesha, K., Gandman, A., Prell, J. S., Prendergast, D., Neumark, D. M. \& Leone, S. R. (2016). J. Opt. Soc. Am. B, 33, C57-C64.

Brodsky, C. N., Hadt, R. G., Hayes, D., Reinhart, B. J., Li, N., Chen, L. X. \& Nocera, D. G. (2017). Proc. Natl Acad. Sci. USA, 114, 38553860.

Bunker, G. (2010). Introduction to XAFS: A Practical Guide to X-ray Absorption Fine Structure Spectroscopy. Cambridge University Press.

Carlotto, S., Floreano, L., Cossaro, A., Dominguez, M., Rancan, M., Sambi, M. \& Casarin, M. (2017). Phys. Chem. Chem. Phys. 19, 24840-24854.

Chábera, P., Kjaer, K. S., Prakash, O., Honarfar, A., Liu, Y., Fredin, L. A., Harlang, T. C. B., Lidin, S., Uhlig, J., Sundström, V., Lomoth, R., Persson, P. \& Wärnmark, K. (2018). J. Phys. Chem. Lett. 9, 459463.

Chakrabarty, R., Bora, S. J. \& Das, B. K. (2007). Inorg. Chem. 46, 9450-9462.

Chatterley, A. S., Lackner, F., Pemmaraju, C. D., Neumark, D. M., Leone, S. R. \& Gessner, O. (2016). J. Phys. Chem. A, 120, 95099518.

Chiuzăian, S. G., Ghiringhelli, G., Dallera, C., Grioni, M., Amann, P., Wang, X., Braicovich, L. \& Patthey, L. (2005). Phys. Rev. Lett. 95, 197402.

Cirri, A., Husek, J., Biswas, S. \& Baker, L. R. (2017). J. Phys. Chem. C, 121, 15861-15869.

Cushing, S. K., Lee, A., Porter, I. J., Carneiro, L. M., Chang, H. T., Zürch, M. \& Leone, S. R. (2019). J. Phys. Chem. C, 123, 3343-3352.

Cushing, S. K., Porter, I. J., de Roulet, B. R., Lee, A., Marsh, B. M., Szoke, S., Vaida, M. E. \& Leone, S. R. (2020). Sci. Adv. 6, eaay6650.

Davis, R. L., Jayaraman, S., Chaikin, P. M. \& Register, R. A. (2014). Langmuir, 30, 5637-5644.

Delor, M., McCarthy, D. G., Cotts, B. L., Roberts, T. D., Noriega, R., Devore, D. D., Mukhopadhyay, S., De Vries, T. S. \& Ginsberg, N. S. (2017). J. Phys. Chem. Lett. 8, 4183-4190.

Diaz-Acosta, I., Baker, J., Cordes, W. \& Pulay, P. (2001). J. Phys. Chem. A, 105, 238-244.

Diaz-Acosta, I., Baker, J., Hinton, J. F. \& Pulay, P. (2003). Spectrochim. Acta A Mol. Biomol. Spectrosc. 59, 363-377.

Dwyer, J. R. \& Harb, M. (2017). Appl. Spectrosc. 71, 2051-2075.

Geneaux, R., Marroux, H. J. B., Guggenmos, A., Neumark, D. M. \& Leone, S. R. (2019). Philos. Trans. R. Soc. A. 377, 20170463.

Groot, F. de \& Kotani, A. (2008). Core Level Spectroscopy of Solids. Boca Raton: CRC Press.

Gu, X., Shaw, L., Gu, K., Toney, M. F. \& Bao, Z. (2018). Nat. Commun. 9, 534.

Hadt, R. G., Hayes, D., Brodsky, C. N., Ullman, A. M., Casa, D. M., Upton, M. H., Nocera, D. G. \& Chen, L. X. (2016). J. Am. Chem. Soc. 138, 11017-11030.

Henke, B. L., Gullikson, E. M. \& Davis, J. C. (1993). At. Data Nucl. Data Tables, 54, 181-342.

Huibers, P. D. T. \& Shah, D. O. (1997). Langmuir, 13, 5995-5998.

Imahori, H. (2004). J. Phys. Chem. B, 108, 6130-6143.

Ito, F., Yamamoto, K., Kogasaka, Y. \& Katoh, R. (2018). Langmuir, 34, 8281-8287.

Jaeger, F. M. \& van Dijk, J. A. (1936). Z. Anorg. Allge. Chem. 227, 273-327.

Jiang, C. M., Baker, L. R., Lucas, J. M., Vura-Weis, J., Alivisatos, A. P. \& Leone, S. R. (2014). J. Phys. Chem. C, 118, 22774-22784.

Jones, S. H., King, D. \& Ward, A. D. (2013). Phys. Chem. Chem. Phys. 15, 20735-20741.

Josefsen, L. B. \& Boyle, R. W. (2008). Met.-Based Drugs, 2008, 276109.

Juris, A. V. B., Balzani, V., Barigelletti, F., Campagna, S., Belser, P. \& von Zelewsky, A. (1988). Coord. Chem. Rev. 84, 85-277.

Kanan, M. W. \& Nocera, D. G. (2008). Science, 321, 1072-1075.

Khodaparast, S., Boulogne, F., Poulard, C. \& Stone, H. A. (2017). Phys. Rev. Lett. 119, 154502. 
Khusnutdinova, J. R., Luo, J., Rath, N. P. \& Mirica, L. M. (2013). Inorg. Chem. 52, 3920-3932.

Kikas, A., Ruus, R., Saar, A., Nõmmiste, E., Käämbre, T. \& Sundin, S. (1999). J. Electron Spectrosc. Relat. Phenom. 101-103, 745-749.

Kubin, M., Guo, M., Ekimova, M., Baker, M. L., Kroll, T., Källman, E., Kern, J., Yachandra, V. K., Yano, J., Nibbering, E. T. J., Lundberg, M. \& Wernet, P. (2018). Inorg. Chem. 57, 5449-5462.

Kubin, M., Kern, J., Guo, M., Källman, E., Mitzner, R., Yachandra, V. K., Lundberg, M., Yano, J. \& Wernet, P. (2018). Phys. Chem. Chem. Phys. 20, 16817-16827.

Landau, L. \& Levich, B. (1942). Acta Physicochim. URSS, 17, 42-54.

Lin, L., Husek, J., Biswas, S., Baumler, S. M., Adel, T., Ng, K. C., Baker, L. R. \& Allen, H. C. (2019). J. Am. Chem. Soc. 141, 1352513535.

Lin, M. F., Verkamp, M. A., Leveillee, J., Ryland, E. S., Benke, K., Zhang, K., Weninger, C., Shen, X., Li, R., Fritz, D., Bergmann, U., Wang, X., Schleife, A. \& Vura-Weis, J. (2017). J. Phys. Chem. C, 121, 27886-27893.

Lin, M.-F., Verkamp, M. A., Ryland, E. S., Zhang, K. \& Vura-Weis, J. (2016). J. Opt. Soc. Am. B, 33, 1986.

McAlpin, J. G., Stich, T., Ohlin, C. A., Surendranath, Y., Nocera, D. G., Casey, W. H. \& Britt, R. D. (2011). J. Am. Chem. Soc. 133, 1544415452.

McCusker, J. K. (2019). Science, 363, 484-488.

Miaja-Avila, L., O’Neil, G. C., Joe, Y. I., Alpert, B. K., Damrauer, N. H., Doriese, W. B., Fatur, S. M., Fowler, J. W., Hilton, G. C., Jimenez, R., Reintsema, C. D., Schmidt, D. R., Silverman, K. L., Swetz, D. S., Tatsuno, H. \& Ullom, J. N. (2016). Phys. Rev. X, 6, 031047.

Nguyen, A. I., Wang, J., Levine, D. S., Ziegler, M. S. \& Tilley, T. D. (2017). Chem. Sci. 8, 4274-4284.

Nguyen, A. I., Ziegler, M. S., Oña-Burgos, P., Sturzbecher-Hohne, M., Kim, W., Bellone, D. E. \& Tilley, T. D. (2015). J. Am. Chem. Soc. 137, 12865-12872.

Norrman, K., Ghanbari-Siahkali, A. \& Larsen, N. B. (2005). Аnnu. Rep. Prog. Chem. Sect. C. 101, 174-201.

Principi, E., Giangrisostomi, E., Mincigrucci, R., Beye, M., Kurdi, G., Cucini, R., Gessini, A., Bencivenga, F. \& Masciovecchio, C. (2018). Phys. Rev. B, 97, 174107.

Ryland, E. S., Lin, M. F., Verkamp, M. A., Zhang, K., Benke, K., Carlson, M. \& Vura-Weis, J. (2018). J. Am. Chem. Soc. 140, 46914696.
Ryland, E. S., Zhang, K. \& Vura-Weis, J. (2019). J. Phys. Chem. A, 123, 5214-5222.

Schiffmann, A., Toulson, B. W., Knez, D., Messner, R., Schnedlitz, M., Lasserus, M., Hofer, F., Ernst, W. E., Gessner, O. \& Lackner, F. (2020). J. Appl. Phys. 127, 184303.

Sham, T. K., Yang, B. X., Kirz, J. \& Tse, J. S. (1989). Phys. Rev. A, 40, 652-669.

Smith, J. W. \& Saykally, R. J. (2017). Chem. Rev. 117, 13909-13934.

Smith, P. F., Hunt, L., Laursen, A. B., Sagar, V., Kaushik, S., Calvinho, K. U. D., Marotta, G., Mosconi, E., De Angelis, F. \& Dismukes, G. C. (2015). J. Am. Chem. Soc. 137, 15460-15468.

Stafford, C. M., Roskov, K. E., Epps, T. H. \& Fasolka, M. J. (2006). Rev. Sci. Instrum. 77, 023908.

Törmä, P. T., Sipilä, H. J., Mattila, M., Kostamo, P., Kostamo, J., Kostamo, E., Lipsanen, H., Nelms, N., Shortt, B., Bavdaz, M. \& Laubis, C. (2013). IEEE Trans. Nucl. Sci. 60, 1311-1314.

Ullman, A. M., Liu, Y., Huynh, M., Bediako, D. K., Wang, H., Anderson, B. L., Powers, D. C., Breen, J. J., Abruña, H. D. \& Nocera, D. G. (2014). J. Am. Chem. Soc. 136, 17681-17688.

Väyrynen, K., Hatanpää, T., Mattinen, M., Heikkilä, M., Mizohata, K., Meinander, K., Räisänen, J., Ritala, M. \& Leskelä, M. (2018). Chem. Mater. 30, 3499-3507.

Vignaud, G., Chebil, M. S., Bal, J. K., Delorme, N., Beuvier, T., Grohens, Y. \& Gibaud, A. (2014). Langmuir, 30, 11599-11608.

Vura-Weis, J., Jiang, C. M., Liu, C., Gao, H., Lucas, J. M., de Groot, F. M. F., Yang, P., Alivisatos, A. P. \& Leone, S. R. (2013). J. Phys. Chem. Lett. 4, 3667-3671.

Wang, H., Young, A. T., Guo, J., Cramer, S. P., Friedrich, S., Braun, A. \& Gu, W. (2013). J. Synchrotron Rad. 20, 614-619.

Wang, R. P., Liu, B., Green, R. J., Delgado-Jaime, M. U., Ghiasi, M., Schmitt, T., van Schooneveld, M. M. \& de Groot, F. M. F. (2017). J. Phys. Chem. C, 121, 24919-24928.

Wenger, O. S. (2019). Chem. Eur. J. 25, 6043-6052.

Wilson, K. R., Rude, B. S., Catalano, T., Schaller, R. D., Tobin, J. G., Co, D. T. \& Saykally, R. J. (2001). J. Phys. Chem. B, 105, 3346-3349.

Zhang, K., Ash, R., Girolami, G. S. \& Vura-Weis, J. (2019). J. Am. Chem. Soc. 141, 17180-17188.

Zhang, K., Lin, M. F., Ryland, E. S., Verkamp, M. A., Benke, K., de Groot, F. M. F., Girolami, G. S. \& Vura-Weis, J. (2016). J. Phys. Chem. Lett. 7, 3383-3387.

Zhang, W., Lai, W. \& Cao, R. (2017). Chem. Rev. 117, 3717-3797.

Zheng, B., Tang, F., Luo, J., Schultz, J. W., Rath, N. P. \& Mirica, L. M. (2014). J. Am. Chem. Soc. 136, 6499-6504. 